\title{
Expanded Use of a Battery-Powered Two-Electrode Emitter Cell for Electrospray Mass Spectrometry
}

\author{
Vilmos Kertesz and Gary J. Van Berkel \\ Organic and Biological Mass Spectrometry Group, Chemical Sciences Division, Oak Ridge National \\ Laboratory, Oak Ridge, Tennessee, USA
}

\begin{abstract}
A battery-powered, controlled-current, two-electrode electrochemical cell containing a porous flow-through working electrode with high surface area and multiple auxiliary electrodes with small total surface area was incorporated into the electrospray emitter circuit to control the electrochemical reactions of analytes in the electrospray emitter. This cell system provided the ability to control the extent of analyte oxidation in positive ion mode in the electrospray emitter by simply setting the magnitude and polarity of the current at the working electrode. In addition, this cell provided the ability to effectively reduce analytes in positive ion mode and oxidize analytes in negative ion mode. The small size, economics, and ease of use of such a battery-powered controlled-current emitter cell was demonstrated by powering a single resistor and switch circuit with a small-size, $3 \mathrm{~V}$ watch battery, all of which might be incorporated on the emitter cell. (J Am Soc Mass Spectrom 2006, 17, 953-961) (C) 2006 American Society for Mass Spectrometry
\end{abstract}

$\mathrm{E}$ lectrochemistry is an inherent part of the normal operation of an electrospray ion source as typically configured for electrospray mass spectrometry (ES-MS) [1, 2]. Oxidation reactions in positive ion mode and reduction reactions in negative ion mode are the predominate reactions at the emitter electrode contact (i.e., the working electrode in this system) that supply the excess of one ion polarity in solution required to maintain the quasi-continuous production of unipolar charged droplets and subsequently gas-phase ions.

Our interest in this electrochemical process is aimed towards better understanding the process to devise means to control it for analytical advantage. The electrochemical reactions at the emitter electrode alter the composition of the solution being electrosprayed, and they can also directly involve the analytes being investigated. Thus, under certain conditions, with particular types of analytes, the electrochemical reactions in the ES ion source can have a significant influence on the identity and abundance of ions observed in an ES mass spectrum $[1,3,4]$. In particular, we have been interested in controlling direct heterogeneous electron-transfer chemistry of the analytes under study and their potential homogeneous chemical follow up reactions.

Published online May 12, 2006

Address reprint requests to Dr. V. Kertesz, Organic and Biological Mass Spectrometry Group, Chemical Sciences Division, Oak Ridge National Laboratory, Oak Ridge, Tennessee 37831-6131, USA. E-mail: kerteszv@ornl.gov
Basic principles of electrochemistry dictate [5] and ES-MS experimentation and calculation [3] have shown that varied degrees of control over the electrochemical processes involving the analytes can be achieved by managing one or more of three basic parameters, viz., mass transport to the ES emitter electrode, the magnitude of the current (more precisely, current density) at the ES emitter electrode, and the ES emitter electrode potential. In our most recent research efforts, we have developed a porous flow-through (PFT) electrode emitter [6, 7], replacing the standard capillary electrode emitter, to provide very efficient mass transport of analytes in solution to the electrode even at flow rates approaching $1 \mathrm{~mL} / \mathrm{min}$. With this emitter electrode design all of the analyte in solution will contact the surface of the PFT electrode on passage through the emitter and very efficient oxidation or reduction of analytes can be achieved as long as the reactions are not current limited, limited by the interfacial electrode potential, or limited by other reaction rate considerations.

A PFT electrode emitter enhances the ability to directly involve the analytes under study in the electrochemistry of the ES process. However, one would like to use this basic electrode configuration as a general ES emitter so that it need not be replaced for experiments in which analyte electrochemistry is not of interest or is to be avoided. Control over which reactions can take place at the emitter electrode, and the rate at which they take place, is achieved by controlling the interfacial potential of the electrode. This can be accomplished to some degree with a single electrode system by limiting the magnitude of the current at the emitter electrode 
through adjustable parameters like solution conductivity or ES voltage drop. Lower current magnitudes either current limit the reaction (Faraday's law) or lower the current density at the electrode so that the potential at the electrode drops to a level lower than that required for the analyte reaction (but still sufficient for another reaction, e.g., solvent electrochemistry, to provide the required current). Another means to control the potential with a single electrode emitter is through the use of redox buffers $[8,9]$.

With a small surface area auxiliary electrode and a reference electrode in addition to the PFT electrode in the emitter cell, precise control of the PFT working electrode potential can be maintained with a potentiostat. We have demonstrated such a controlled-potential electrochemistry (CPE)-ES emitter operated with a floated potentiostat powered by $120 \mathrm{~V}$ main power [10, 11]. Cole's group discussed a CPE-ES emitter of a different design controlled with a floated battery-powered potentiostat $[12,13]$. We found that use of a small area auxiliary electrode was crucial in our emitter cell design because analyte reactions that were excluded at the PFT working electrode would occur at the auxiliary electrode unless mass transport to that electrode was hindered. By keeping the auxiliary electrode area small, reactions of the dilute analyte species are kept to a minimum at flow rates greater than about $30 \mu \mathrm{L} / \mathrm{min}$ [10]. Solvents and solution additives react to supply the required current at this electrode.

Emitter working electrode potential control intermediate to that of the single electrode emitter and to that of the CPE-ES system can be obtained using a two-electrode emitter system and a very simple battery-powered voltage or current supply. In this case, one of the two electrodes is used as the working electrode, while the other acts simultaneously as the quasi-reference and the auxiliary electrode. This configuration results in limited control over the working electrode potential because the potential of the quasi-reference electrode is not well-defined. The potential of the latter electrode is a function of many parameters including the current density (defined by applied voltage or current and electrode surface area), solution conductivity, solution composition, etc. However, one statement is always true regarding such a two-electrode cell: on either electrode a cathodic current results in reduction and an anodic current results in oxidation. We demonstrated a floated ES emitter system utilizing two-tubular stainless electrodes in the mid-1990s [14] and more recently Brajter-Toth and coworkers [15] discussed a very similar two-tubular electrode emitter cell. In each case, these simple battery-powered cells were used only to either enhance the mass spectral signal level of the molecular ion of analytes that could be ionized (oxidized) by electron-transfer or to follow the reaction path of analytes that could be oxidized in the emitter cell.

In this paper, we use the same emitter cell with a PFT working electrode as in our previous CPE-ES studies $[10,11]$, but operate it in a two-electrode

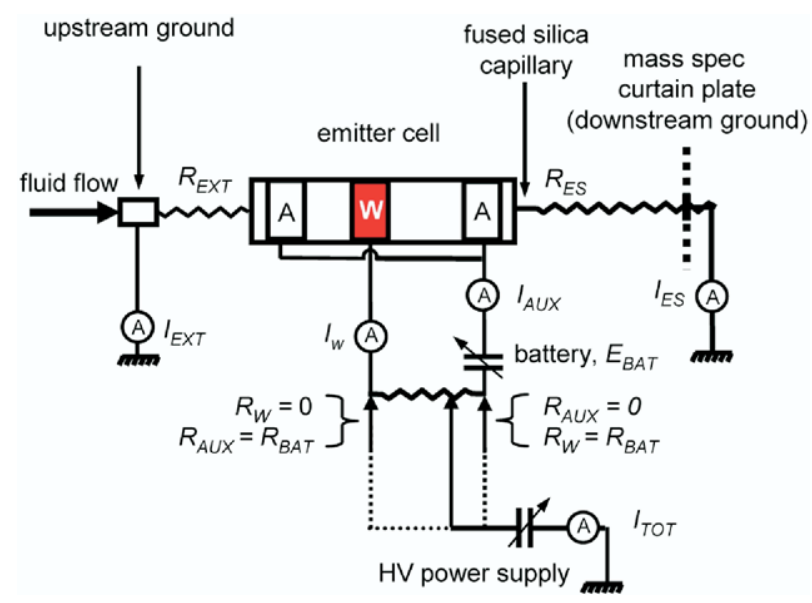

Figure 1. Diagram of electrical circuit for the CCE-ES emitter. W and $\mathrm{A}$ represent the working and auxiliary electrodes in the electrochemical cell, respectively. $I_{W}, I_{A U X}, I_{E S}$, and $I_{E X T}$ are the currents in the working electrode, auxiliary electrode, ES spray current, and upstream external current loop, respectively. Other parameters are defined in text.

mode, powered by a battery floated at the ES high voltage (Figures 1 and 2). The two circuits we used for this controlled-current electrochemistry (CCE)-ES emitter setup provided the ability to monitor the current conditions at each electrode and thereby correlate these conditions with the collected mass spectra. Just as in the case of the previous twoelectrode ES emitter systems reported [14, 15] and in the case of our three-electrode emitter cell controlled by a potentiostat, $[10,11]$, this CCE-ES system provides the ability to enhance the oxidation of analytes in positive ion mode. Also, like our potentiostat controlled three-electrode emitter cell, this CCE-ES emitter cell provides the ability to turn off analyte oxidation in positive ion mode or reduction in negative ion mode. Furthermore, one also has the ability to reduce analytes in positive ion mode and oxidize analytes in negative ion mode. In the present case, this control was gained by controlling the magnitude and polarity of the current at the large surface area working electrode rather than controlling the working electrode potential directly. The practicality and economics of such a battery-powered, two-electrode CCE-ES emitter system is further demonstrated with a simple circuit that includes just one resistor and a toggle switch, and is powered by a small-size $3 \mathrm{~V}$ watch battery, all of which are, or could be made, small enough to fit on the body of the emitter cell.

\section{Experimental}

\section{Samples and Reagents}

Reserpine (Compound 1, Aldrich, Milwaukee, WI), methylene blue (Compound 2, Aldrich), and 3,4dihydroxybenzoic acid (Compound 4, Aldrich) were obtained commercially and used without further pu- 
rification. Solutions were prepared using acetonitrile (Burdick and Jackson, Muskegon, MI), water (Burdick and Jackson), ammonium acetate (99.999\%, Aldrich), and acetic acid (PPB/Teflon grade, Aldrich).

(a)

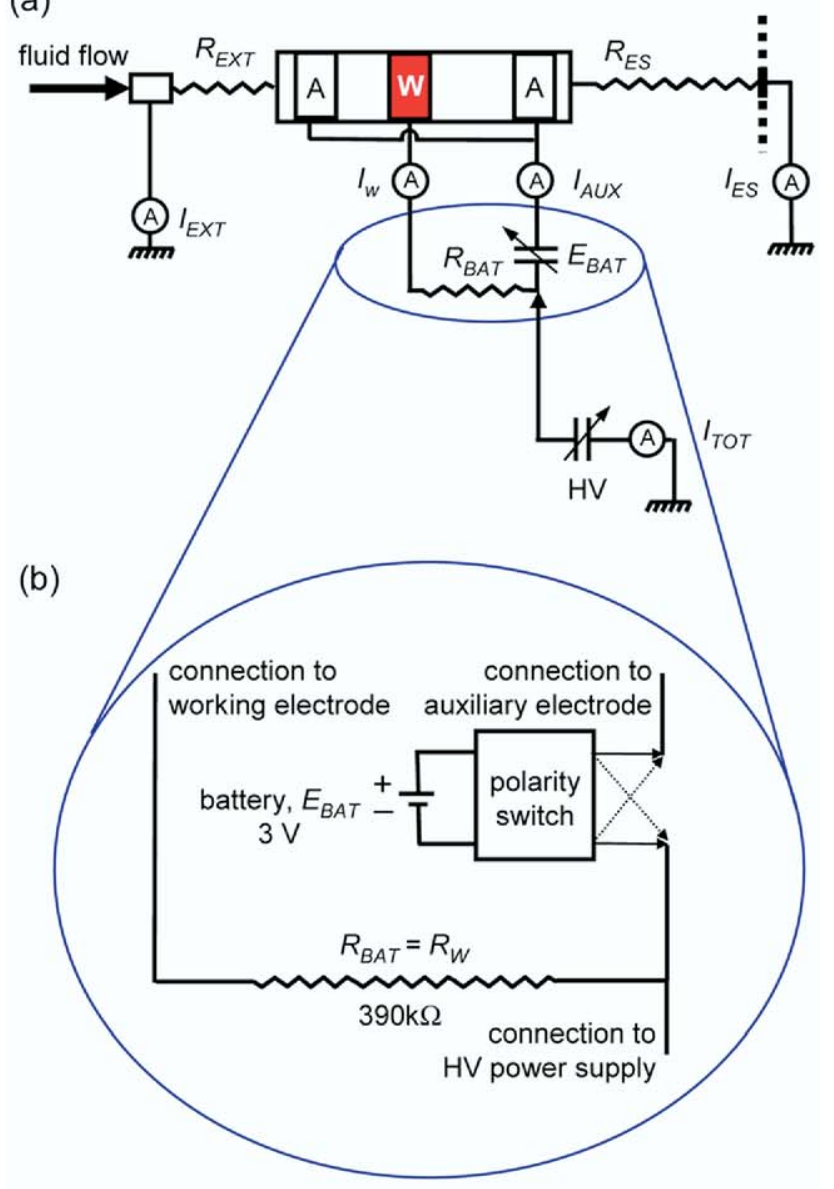

(c)
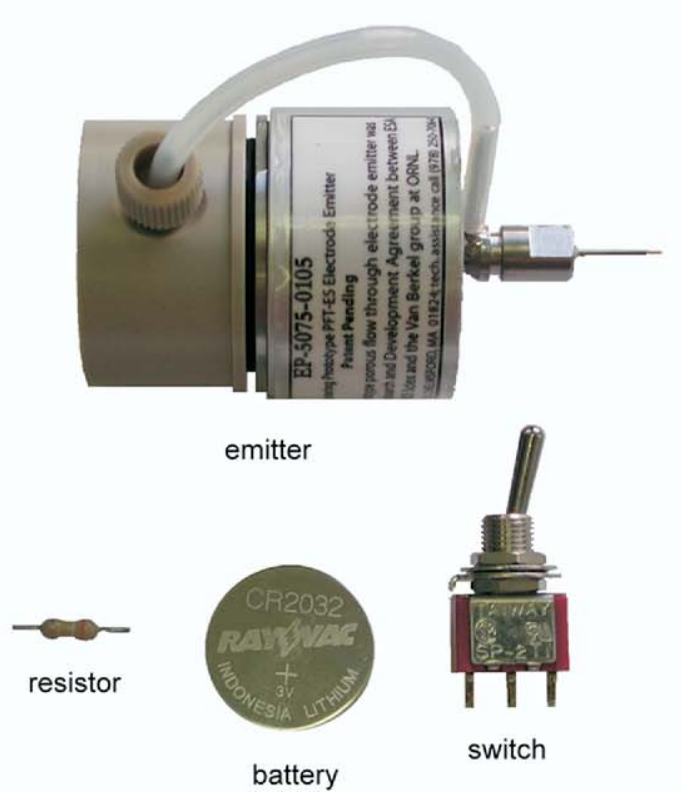

\section{ES-MS}

Experiments were performed on a PE Sciex API 165 single quadrupole mass spectrometer (MDS Sciex, Concord, Ontario, Canada). An HP 1090 Series II LC system (Hewlett-Packard, Palo Alto, CA) was used to deliver solvent and analyte solutions to the ion source. All data were acquired using a modified TurbolonSpray source incorporating a two-electrode controlled-current emitter cell configured for pneumatic nebulization. This emitter cell incorporating a porous carbon flow-through working electrode has been described in detail elsewhere $[10,11]$. For this work, the four small palladium electrodes on each side of the working electrode (two normally used as auxiliary electrodes and two as quasireference electrodes) were connected together in the circuit as the auxiliary electrode. The solution exited the cell and was sprayed through a $3.5 \mathrm{~cm}$ length of $50 \mu \mathrm{m}$ i.d., $360 \mu \mathrm{m}$ o.d. fused silica capillary with a Taper Tip (New Objective, Inc, Woburn, MA). To protect the working electrode emitter from plugging, a precolumn filter $(0.5 \mu \mathrm{m}$ frit $)$ was placed upstream of the emitter cell in all experiments.

The diagram of the battery-powered circuit used with the CCE-ES emitter is shown in Figure 1. The current $\left(I_{B A T}\right)$ in the battery circuit (containing the working and auxiliary electrodes and the battery) was defined by the resistor total resistance $\left(R_{B A T}\right)$ and the solution resistance $\left(R_{S O L}\right)$ between the two electrodes. $R_{B A T}$ was realized as a resistor chain built by serially connecting $100 \mathrm{k} \Omega$ (5 pieces), $560 \mathrm{k} \Omega, 1 \mathrm{M} \Omega$, and $2.2 \mathrm{M} \Omega$ resistors. An 6LR61 type $9 \mathrm{~V}$ battery (Duracell, Bethel, $\mathrm{CT}$ ) was used to power this extra circuit. In experiments using 3,4-dihydroxybenzoic acid, the negative pole of the battery was coupled to the auxiliary electrode, while in experiments using reserpine and methylene blue, the positive pole of the battery was coupled to the auxiliary electrode. Changing the resistance in the working $\left(R_{W}\right)$ and auxiliary $\left(R_{A U X}\right)$ leg of the circuit, i.e., distributing $R_{B A T}$ between these two circuit legs, was accomplished by connecting the ES high voltage lead to different points of the resistance chain. The second circuit used to power the CCE-ES emitter utilized a CR2032 type $3 \mathrm{~V}$ watch battery (Rayovac, Madison, WI) and a single 390 $k \Omega$ resistor (Figure 2). The polarity of the battery in the

Figure 2. (a) Diagram of electrical circuit for the CCE-ES emitter using a $3 \mathrm{~V}$ watch battery. $\mathrm{W}$ and $\mathrm{A}$ represent the working and auxiliary electrodes in the electrochemical cell, respectively. $I_{W}, I_{A U X}, I_{E S}$, and $I_{E X T}$ are the currents in the working electrode, auxiliary electrode, ES spray current, and upstream external current loop, respectively. The total current at the emitter $\left(I_{T O T}=I_{E S}+I_{E X T}\right)$ is divided between $I_{W}$ and $I_{A U X}$. (b) Details on the battery circuit part of the system showing the polarity change switch and the $390 \mathrm{k} \Omega$ resistor in the working electrode leg circuit. (c) Photograph of the circuit components used to build the $3 \mathrm{~V}$ watch battery powered circuit showing the relative size of the parts and the emitter cell. Other parameters are defined in text. 
circuit could be reversed using a double-pole, doublestate, type 35-018 toggle switch (GC/Waldom, Inc., Rockford, IL), as shown by the dotted arrows in Figure $2 \mathrm{~b}$. To reduce shock hazard, the whole battery circuit was placed in a plexiglass box and the switch was operated by an isolated toggle.

The current values in the working $\left(I_{W}\right)$ and auxiliary $\left(I_{A U X}\right)$ electrode circuit legs were simultaneously measured by inserting GB Instruments model GDT-11 multimeters (Gardner Bender, Milwaukee, WI) into the respective circuits. The current in the battery circuit $\left(I_{B A T}\right)$ when no high voltage was applied to the emitter was also recorded. The ES current $\left(I_{E S}\right)$ was measured on the mass spectrometer side of the circuit by grounding the curtain plate (normally $1.0 \mathrm{kV}$ ) of the mass spectrometer through a Keithley model 610C electrometer (Cleveland, $\mathrm{OH}$ ) and lowering the emitter voltage by $1.0 \mathrm{kV}$. The spray capillary was moved laterally beyond the sampling orifice so all of the charged droplets impacted the curtain plate. The current in the external upstream current loop $\left(I_{E X T}\right)$ was measured by connecting the upstream ground of the ES ion source to ground through the same electrometer with no other conditions altered.

\section{Safety}

All electrical circuit components that float at the ES high voltage should be handled with extreme care and preferably isolated from the user with appropriate shields and safety interlocks. The electrospray voltage was set to $0 \mathrm{~V}$ before any changes were made in a circuit to avoid a shock hazard.

\section{Results and Discussion}

Figure 1 shows a schematic of the entire CCE-ES setup including the battery, resistor chain, the mass spectrometer, and the various current paths. As defined here, the total current, $I_{T O T}$, at the electrodes making high voltage contact to solution in the ES emitter is the sum of the ES current, $I_{E S}$, in the current loop formed between the emitter electrode and the curtain plate (the mass spectrometer counter electrode), and the external upstream current, $I_{E X T}$, in the current loop between the emitter

Table 1. Electrospray $\left(I_{E S}\right)$, upstream loop $\left(I_{E X T}\right)$, working electrode $\left(I_{W}\right)$ and auxiliary electrode $\left(I_{A U X}\right)$ currents measured with different resistance applied in the working electrode leg $\left(R_{W}\right)$ of the CCE-ES emitter circuit. $R_{B A T}=R_{W}+R_{A U X}=4.26$ $\mathrm{M} \Omega$. Data obtained using large volume injections $(500 \mu \mathrm{L})$ of 5 $\mu \mathrm{M}$ reserpine at $50 \mu \mathrm{L} / \mathrm{min}$ in $50 / 50(\mathrm{v} / \mathrm{v})$ acetonitrile/water containing $5.0 \mathrm{mM}$ ammonium acetate and $0.75 \%$ by volume acetic acid. See the corresponding mass spectra in Figure $3 \mathrm{a}$

\begin{tabular}{lrcccc}
\hline$R_{W}(\mathrm{M} \Omega)$ & $I_{W}(\mu \mathrm{A})$ & $R_{A U X}(\mathrm{M} \Omega)$ & $I_{A U X}(\mu \mathrm{A})$ & $I_{E X T}(\mu \mathrm{A})$ & $I_{E S}(\mu \mathrm{A})$ \\
\hline \hline 0 & 5.3 & 4.26 & 2.4 & -7.5 & -0.2 \\
0.5 & 4.4 & 3.76 & 3.3 & -7.5 & -0.2 \\
2.06 & 1.8 & 2.2 & 5.9 & -7.5 & -0.2 \\
4.26 & -1.8 & 0 & 9.5 & -7.5 & -0.2 \\
\hline
\end{tabular}

Table 2. Electrospray $\left(I_{E S}\right)$, upstream loop $\left(I_{E X T}\right)$, working electrode $\left(I_{W}\right)$ and auxiliary electrode $\left(I_{A U X}\right)$ currents measured with different resistance applied in the working electrode leg $\left(R_{W}\right)$ of the CCE-ES emitter circuit. $R_{B A T}=R_{W}+R_{A U X}=2.06$ $\mathrm{M} \Omega$. Data obtained using large volume injections $(500 \mu \mathrm{L})$ of 5 $\mu \mathrm{M}$ reserpine at $50 \mu \mathrm{L} / \mathrm{min}$ in $50 / 50(\mathrm{v} / \mathrm{v})$ acetonitrile/water containing $5.0 \mathrm{mM}$ ammonium acetate and $0.75 \%$ by volume acetic acid. See the corresponding mass spectra in Figure $3 \mathrm{~b}$

\begin{tabular}{lccccc}
\hline$R_{W}(\mathrm{M} \Omega)$ & $I_{W}(\mu \mathrm{A})$ & $R_{A U X}(\mathrm{M} \Omega)$ & $I_{A U X}(\mu \mathrm{A})$ & $I_{E X T}(\mu \mathrm{A})$ & $I_{E S}(\mu \mathrm{A})$ \\
\hline \hline 0 & 2.9 & 2.06 & 4.8 & -7.5 & -0.2 \\
0.5 & 1.4 & 1.56 & 6.3 & -7.5 & -0.2 \\
1.06 & 0 & 1 & 7.7 & -7.5 & -0.2 \\
2.06 & -3.3 & 0 & 11.0 & -7.5 & -0.2 \\
\hline
\end{tabular}

and the upstream ground point in the solution flow stream $\left(I_{T O T}=I_{E S}+I_{E X T}\right)$. These two current loops are also present in the classic ES ion source when the emitter electrode is held at high voltage.

Direct current measurements showed that $I_{T O T}$ was divided between the current realized in the working electrode leg $\left(I_{W}\right)$ and that in the auxiliary electrode leg $\left(I_{A U X}\right)$ without implementing a battery in the circuit [11]. The particular split of $I_{T O T}$ between $I_{W}$ and $I_{A U X}$ was a reflection of the distribution of $R_{B A T}$ (resistance in the resistor chain) between the resistance in the working electrode leg $\left(R_{W}\right)$ and the resistance in the auxiliary electrode leg $\left(R_{A U X}\right)$, i.e., $R_{B A T}=R_{W}+R_{A U X}$. By implementing a battery in the circuit, $I_{W}$ and $I_{A U X}$ were superimposed on $I_{B A T}$ (i.e., the current supplied as a result of the battery in the circuit). As a result, adding the battery allowed the current distribution through the two legs of the cell circuit to be redistributed between the two electrodes.

Note also that $I_{E X T}+I_{E S}+I_{W}+I_{A U X}=0$ (see Tables 1 and 2). By measuring $I_{B A T}$ without high voltage applied $\left(I_{E X T}=0 \mu \mathrm{A}, I_{E S}=0 \mu \mathrm{A}\right)$, the solution resistance $\left(R_{S O L}\right)$ between the two electrodes can be estimated on the basis of eq 1 , if the charge-transfer resistance and the battery's inner resistance $(<1 \mathrm{k} \Omega)$ [16] are negligible:

$$
I_{B A T}=E_{B A T} /\left(R_{B A T}+R_{S O L}\right)
$$

With the electrolyte solution used in this study flowing through the system at $50 \mu \mathrm{L} / \mathrm{min}$, the measured $I_{B A T}$ was $1.8 \mu \mathrm{A}$ when $R_{B A T}$ was $4.26 \mathrm{M} \Omega$ using $E_{B A T}=9 \mathrm{~V}$. The measured $I_{B A T}$ was $-3.3 \mu \mathrm{A}$ when $R_{B A T}$ was 2.06 $\mathrm{M} \Omega$ using $E_{B A T}=-9 \mathrm{~V}$ (negative pole is connected to the working electrode leg). Using these values, 0.74 and $0.66 \mathrm{M} \Omega$ (average: $0.70 \mathrm{M} \Omega$ ) were calculated for $R_{S O L}$, respectively. Considering that the current meters had $0.1 \mu \mathrm{A}$ resolution, the two calculated $R_{S O L}$ values were equal within experimental error. Knowing $R_{S O L}$ allows calculation of the highest current possible when the total circuit resistance, $R_{T O T}=R_{B A T}+R_{S O L}$, is minimal, i.e., $R_{B A T}=0 \mathrm{M} \Omega$ (no extra resistance in the circuit, e.g., $9 \mathrm{~V} / 0.70 \mathrm{M} \Omega=12.9 \mu \mathrm{A})$. This current value can in turn be used to calculate the maximum analyte concentra- 
(a)<smiles>COC(=O)c1cc(OC)c(OC)c(OC)c1</smiles>

(b)

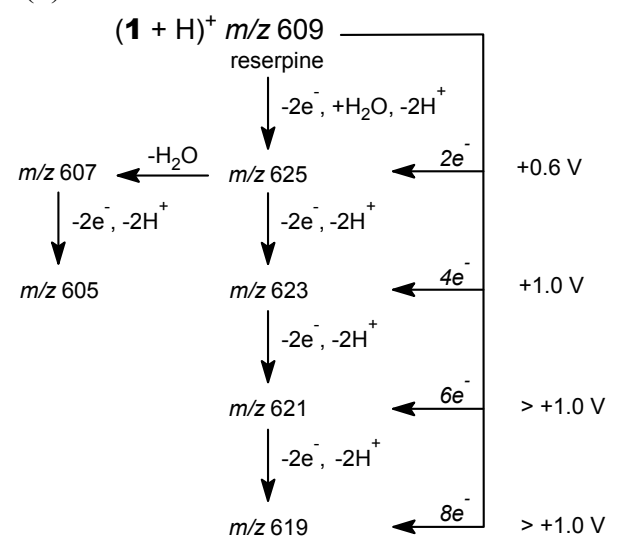

(c)

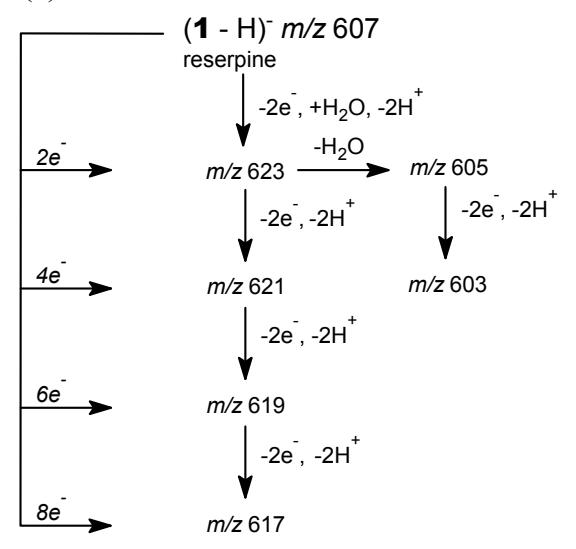

Scheme 1. (a) Reserpine (1) structure, proposed oxidation pathways, oxidation potentials and ions observed in (b) positive and (c) negative ion mode.

tion that can be oxidized/reduced at a given flow rate. The electrolysis current, $I_{100 \%}$, required for complete analyte oxidation (or reduction) in the emitter cell can be calculated by using eq 2

$$
I_{100 \%}=n F v c
$$

where $n$ is the number of electrons transferred, $F$ is the Faraday constant $(96,485 \mathrm{C} / \mathrm{mol}), c$ is the concentration of the analyte, and $v$ is the volumetric flow rate.

\section{Analyte Oxidation in Positive Ion Mode}

The normal operation of the ES ion source dictates that if the analyte is involved in the ion source electrochemistry it will be oxidized in positive ion mode (reduced in negative ion mode) [1]. Controlling the current magnitude and polarity at the large surface area working electrode of the two-electrode cell can be used to either enhance the extent of oxidation or turn off the reaction completely. Table 1 lists the measured values of $I_{W}$, $R_{A U X}, I_{A U X}, I_{E X T}$, and $I_{E S}$ when $R_{W}$ was set at $0,0.5,2.06$, and $4.26 \mathrm{M} \Omega$, with $R_{B A T}=4.26 \mathrm{M} \Omega$. Using eq 2, complete oxidation of a $5 \mu \mathrm{M}$ solution of reserpine (1, $(\mathrm{M}+\mathrm{H})^{+}=m / z$ 609) flowing through the emitter cell at $50 \mu \mathrm{L} / \mathrm{min}$, for reactions involving $2 \mathrm{e}^{-}, 4 \mathrm{e}^{-}, 6 \mathrm{e}^{-}$, or $8 \mathrm{e}^{-}$, was determined to require oxidative currents of $0.80,1.6,2.4$, and $3.2 \mu \mathrm{A}$, respectively (Scheme 1a). Figure $3 a$ shows the reserpine mass spectra obtained when a $5 \mu \mathrm{M}$ reserpine solution was injected into the
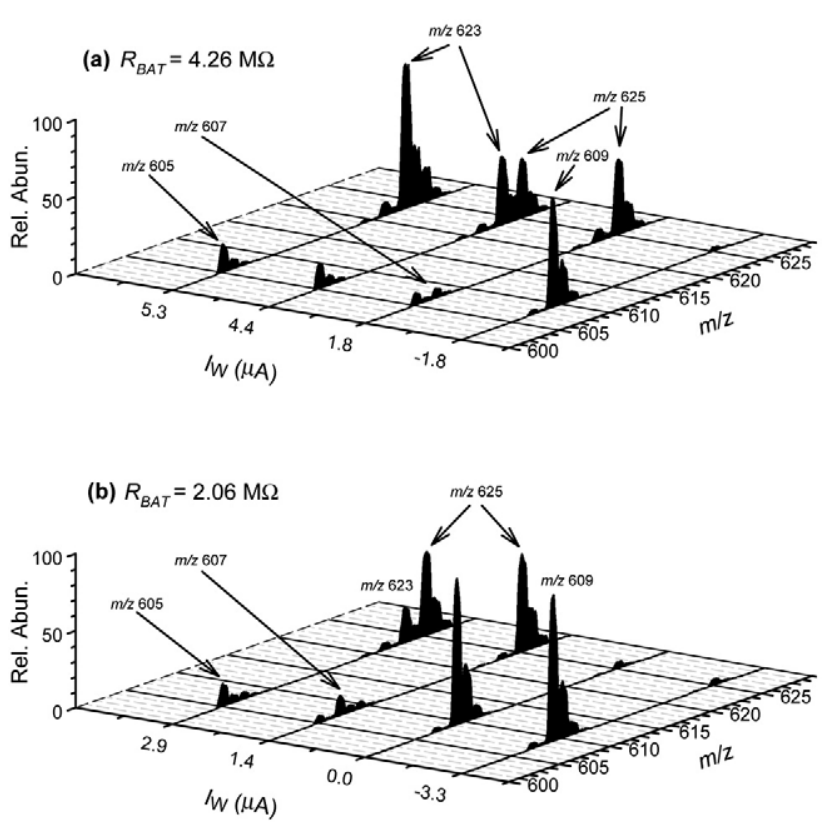

Figure 3. Positive ion mode CCE-ES mass spectra obtained at the plateau region of a $500 \mu \mathrm{L}$ injection of a $5 \mu \mathrm{M}$ solution of reserpine $\left[(\mathbf{1}+\mathrm{H})^{+}=m / z\right.$ 609] in 50/50 (vol/vol) water/acetonitrile, 5.0 $\mathrm{mM}$ ammonium acetate, $0.75 \%$ by volume acetic acid at a flow rate $50 \mu \mathrm{L} / \mathrm{min}$ using the battery circuit with (a) $R_{W}$ set at $0,0.5,2.06$, and $4.26 \mathrm{M} \Omega$ with $R_{B A T}=4.26 \mathrm{M} \Omega$ and (b) $R_{W}$ set at $0,0.5,1.06$, and $2.06 \mathrm{M} \Omega$ with $R_{B A T}=2.06 \mathrm{M} \Omega$ (see Tables 1 and 2). 
(a)

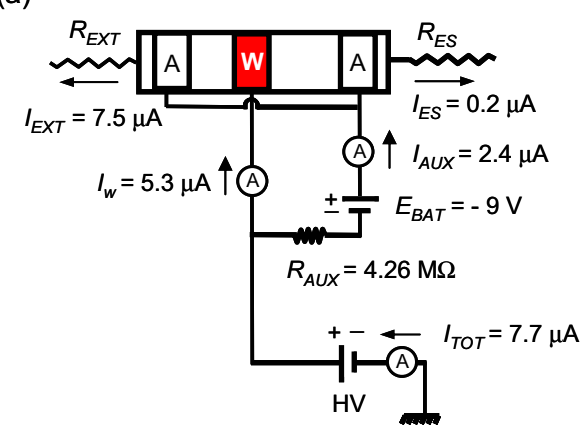

(b)

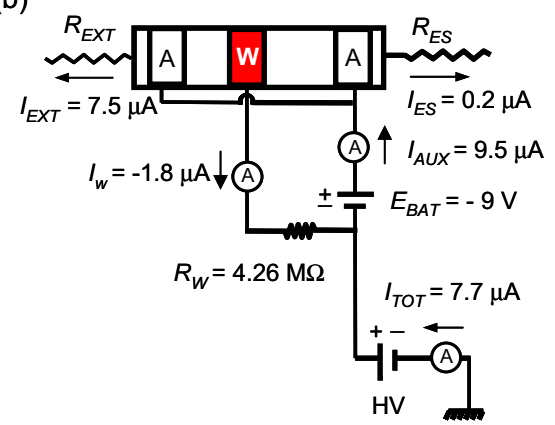

Figure 4. Detailed diagrams of the electrical circuits used for recording mass spectra in Figure 3 a corresponding to (a) $I_{W}=5.3$ $\mu \mathrm{A}\left(R_{W}=0 \mathrm{M} \Omega, R_{A U X}=4.26 \mathrm{M} \Omega\right)$ and $(\mathbf{b}) I_{W}=-1.8 \mu \mathrm{A}\left(R_{W}=\right.$ $4.26 \mathrm{M} \Omega, R_{A U X}=0 \mathrm{M} \Omega$ ).

system under the corresponding circuit conditions in Table 1. Inspection of the current data in the table and the corresponding mass spectra indicate that the extent of compound oxidation correlated with the magnitude of the oxidative current at the working electrode.

These current and mass spectral data are best understood with reference to the circuit diagram in Figure 1 and to the specific circuits for $R_{W}=0$ and $4.26 \mathrm{M} \Omega$ illustrated in Figure $4 a$ and $b$, respectively. When the whole resistance chain was in the working electrode leg $\left(R_{W}=4.26 \mathrm{M} \Omega, R_{A U X}=0 \mathrm{M} \Omega\right.$, Figure $\left.4 \mathrm{~b}\right)$, a reductive current was measured at this electrode $\left(I_{W}=-1.8 \mu \mathrm{A}\right)$ and no reserpine oxidation was observed, even though $I_{A U X}$ was $9.5 \mu \mathrm{A}$. Because the current at the working electrode was reductive, no oxidation of the analyte could take place at this electrode. The current at this electrode was due to reduction of some other component(s) in the solvent system (i.e., solvent and/or supporting electrolyte). Inefficient analyte mass transport to the small surface area auxiliary electrodes inhibited reserpine oxidation at those electrodes at this flow rate. The current measured at the auxiliary electrodes was due to oxidation of the solvent system. When $R_{W}$ was stepped through the resistor chain from 4.26 to $0 \mathrm{M} \Omega$, $I_{W}$ increased from the reductive $-1.8 \mu \mathrm{A}$ to the oxidative $5.3 \mu \mathrm{A}$ (Table 1 ), and the base peak of the corresponding mass spectra in Figure 3a shifted from protonated reserpine $(m / z$ 609) through the two-electron oxidation product $(\mathrm{m} / \mathrm{z} 625)$ to the four-electron oxida- tion product $(\mathrm{m} / \mathrm{z} 623)$ indicating a general increase in the reserpine oxidation efficiency with increasing magnitude of the oxidative current at the working electrode. When the whole resistance chain was in the auxiliary electrode leg $\left(R_{W}=0 \mathrm{M} \Omega, R_{\text {AUX }}=4.26 \mathrm{M} \Omega\right.$, Figure $\left.4 \mathrm{a}\right)$, an oxidative current was measured at both electrodes $\left(I_{W}=5.3 \mu \mathrm{A}, I_{A U X}=2.4 \mu \mathrm{A}\right)$. Because of mass transport issues, all the reserpine oxidation observed in the corresponding mass spectrum (Figure $3 \mathrm{a}, I_{W}=5.3 \mu \mathrm{A}$ ) must have taken place at the working electrode. Some of the current at the working electrode (not enough reserpine to supply all the current, eq 2) and essentially all of the current at the auxiliary electrode was due to oxidation of the solvent system.

Table 2 lists the measured values of $I_{W}, R_{A U X}, I_{A U X}$, $I_{E X T}$, and $I_{E S}$ values when $R_{W}$ was set at $0,0.5,1.06$, and $2.06 \mathrm{M} \Omega$, with $R_{B A T}=2.06 \mathrm{M} \Omega$. Figure $3 \mathrm{~b}$ shows the corresponding reserpine mass spectra. Comparison of $I_{W}$ values in Tables 2 , and the corresponding reserpine oxidation efficiencies apparent in the spectra in Figure $3 \mathrm{~b}$ reveals again that the magnitude and polarity of $I_{W}$ defines the reserpine oxidation efficiency, even if $R_{B A T}$ is changed. $R_{B A T}$ has an important effect by defining $I_{B A T}$ in this extra circuit as $I_{T O T}$ is practically defined by the solution composition, $[6,10,11] I_{B A T}$ defines the current window within which $I_{W}$ can be changed. This observation is well demonstrated by the -1.8 to +5.3 $\mu \mathrm{A}$ and -3.3 to $+2.9 \mu \mathrm{A}$ ranges for $I_{W}$ accessible using $R_{B A T}=4.26$ and $2.06 \mathrm{M} \Omega$, respectively (Tables 1 and 2). The selection of $R_{B A T}$ thus determines the current magnitude range within which the working electrode current can be tuned to achieve the desired efficiency of analyte oxidation or reduction.

\section{Analyte Reduction in Positive Ion Mode/Oxidation in Negative Ion Mode}

The basic CCE-ES emitter system presented here provided an architecture that also made possible the efficient reduction/oxidation of analytes in positive/negative ion mode, respectively. Scheme 2 shows the twoelectron, one-proton reduction of methylene blue cation $\left[(2)^{+}, m / z\right.$ 284] forming Compound 3, which was observed as the protonated molecule at $\mathrm{m} / \mathrm{z} 286$. Figure $5 a$ is the mass spectrum of methylene blue recorded with $R_{W}=0 \mathrm{M} \Omega\left(R_{A U X}=2.06 \mathrm{M} \Omega\right)$ and $E_{B A T}=-9 \mathrm{~V}$. Under these settings, oxidative currents of $I_{W}=2.7 \mu \mathrm{A}$ and $I_{A U X}=5.0 \mu \mathrm{A}$ were measured and reduction of methylene blue was not observed as indicated by the lack of signal at $m / z 286\left[(3+\mathrm{H})^{+}\right]$in Figure 5a. However, with $R_{W}=2.06 \mathrm{M} \Omega\left(R_{A U X}=0 \mathrm{M} \Omega\right)$ a reductive $I_{W}=-3.3 \mu \mathrm{A}$ and oxidative $I_{A U X}=11.0 \mu \mathrm{A}$ were measured. The corresponding mass spectrum indicated efficient reduction of $(2)^{+}$to 3 (Figure $5 \mathrm{~b}$ ). Also, a well-resolved peak at $m / z 285$ was observed in the spectrum. This can be tentatively assigned as the methylene blue radical cation intermediate $\left[(\mathbf{2 H})^{\cdot+}\right]$ formed by one-electron reduction [17]. 
<smiles>CN(C)c1ccc2nc3ccc(N(C)C)cc3[s+]c2c1</smiles>

$(\mathbf{2})^{+}$<smiles>CN(C)c1ccc2c(c1)Sc1cc(N(C)C)ccc1N2</smiles>

3<smiles></smiles>

(2)

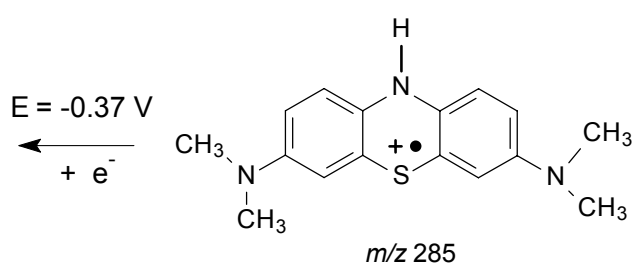

$(\mathbf{2 H})^{\bullet+}$

Scheme 2. Methylene blue (2) structure, oxidation pathway, and ions observed.

Similar observations were made regarding analyte oxidation in negative ion mode. Scheme 3 shows the two-electron, two-proton oxidation of 3,4-dihydroxybenzoic acid (4) forming Compound 5, which was observed as the deprotonated molecule at $\mathrm{m} / \mathrm{z} 151$ [ (5 $\mathrm{H})^{-}$]. Figure $5 \mathrm{c}$ shows the mass spectrum of 4 that was recorded by setting $R_{W}=0 \mathrm{M} \Omega\left(R_{A U X}=2.06 \mathrm{M} \Omega\right)$ and using $E_{B A T}=+9 \mathrm{~V}$. Under these conditions, reductive currents of $I_{W}=-2.6 \mu \mathrm{A}$ and $I_{A U X}=-4.9 \mu \mathrm{A}$ were measured. No oxidation product was observed in the spectrum in agreement with the measured reductive $I_{W}$. However, when $R_{W}$ was set at $2.06 \mathrm{M} \Omega\left(R_{A U X}=0 \mathrm{M} \Omega\right)$, an oxidative $I_{W}=3.4 \mu \mathrm{A}$ and reductive $I_{A U X}=-10.9$
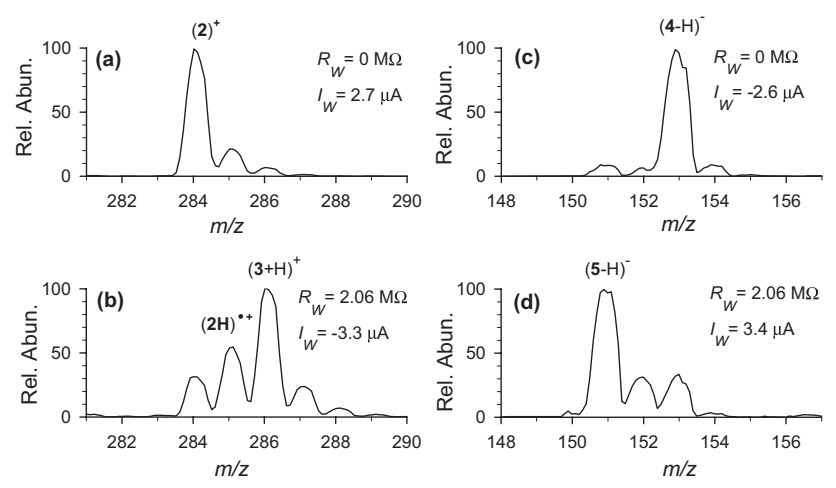

Figure 5. Positive ion mode CCE-ES mass spectra obtained at the plateau region of a $500 \mu \mathrm{L}$ injection of a $5 \mu \mathrm{M}$ solution of methylene blue (2) in 50/50 (vol/vol) water/acetonitrile, $5.0 \mathrm{mM}$ ammonium acetate, $0.75 \%$ by volume acetic acid at a flow rate 50 $\mu \mathrm{L} /$ min using the battery circuit $\left(R_{B A T}=2.06 \mathrm{M} \Omega\right)$ with $R_{W}$ set to (a) $0 \mathrm{M} \Omega$ and (b) $2.06 \mathrm{M} \Omega$. Negative ion mode CCE-ES mass spectra obtained at the plateau region of a $500 \mu \mathrm{L}$ injection of a 20 $\mu \mathrm{M}$ solution of 3,4-dihydroxybenzoic acid (4) in 50/50 (vol/vol) water/acetonitrile, $5.0 \mathrm{mM}$ ammonium acetate at a flow rate 50 $\mu \mathrm{L} /$ min using the battery circuit $\left(R_{B A T}=2.06 \mathrm{M} \Omega\right)$ with $R_{W}$ set to (c) $0 \mathrm{M} \Omega$ and (d) $2.06 \mathrm{M} \Omega$.

$\mu \mathrm{A}$ were measured. The base peak in the corresponding mass spectrum was observed at $m / z 151$ indicating very efficient oxidation of $\mathbf{4}$ to 5 at the working electrode (Figure 5d) due to the oxidative $I_{W}$.

\section{Watch Battery Circuit}

To demonstrate the practical implementation, economics, and ease of use of a battery-powered CCE-ES emitter cell, we built a simple circuit that included only a $390 \mathrm{k} \Omega$ resistor, a toggle switch, and a small-size $3 \mathrm{~V}$, CR 2032 type lithium watch battery (Figure 2). The switch enabled simple reversal of the polarity of the battery in the circuit resulting in either an oxidative or a reductive current at the working electrode. This circuit enabled a basic turn on/turn off control for analyte electrochemistry using our two-electrode emitter cell.

Figure 6a shows the negative ion mode mass spectrum of $5 \mu \mathrm{M}$ reserpine obtained while applying $E_{B A T}=$ $-3 \mathrm{~V}$, which resulted in $I_{W}=-9.8 \mu \mathrm{A}$. The mass spectrum exhibited only one peak at $\mathrm{m} / \mathrm{z} 607$ that corresponded to deprotonated reserpine, $(\mathbf{1}-\mathrm{H})^{-}$.<smiles>O=C(O)c1ccc(O)c(O)c1</smiles>

$(4-H)^{-}=m / z 153$

\section{4}

Scheme 3. 3,4-Dihydroxybenzoic acid (4) structure, oxidation pathway, and ions observed. 

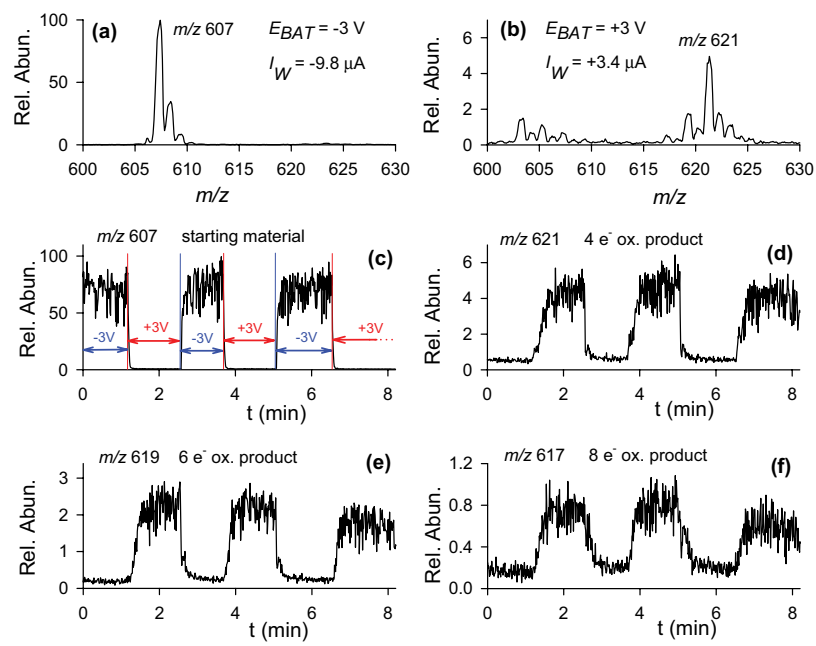

Figure 6. Negative ion mode CCE-ES mass spectra obtained at the plateau region of a $500 \mu \mathrm{L}$ injection of a $5 \mu \mathrm{M}$ solution of reserpine $\left[(1-\mathrm{H})^{-}=\mathrm{m} / \mathrm{z}\right.$ 607] in $50 / 50$ (vol/vol) water/ acetonitrile, $5.0 \mathrm{mM}$ ammonium acetate at a flow rate $100 \mu \mathrm{L} / \mathrm{min}$ using (a) $E_{B A T}=-3 \mathrm{~V}$ and (b) $E_{B A T}=+3 \mathrm{~V}$. Selected ion monitoring ion current profiles for the (c) original reserpine compound at $m / z 607 ;$ (d) $4 \mathrm{e}^{-}$oxidation product at $m / z 621 ;$ (e) $6 \mathrm{e}^{-}$ oxidation product at $\mathrm{m} / \mathrm{z} 619$ and (f) $8 \mathrm{e}^{-}$oxidation product at $\mathrm{m} / \mathrm{z}$ 617.

Figure $6 \mathrm{~b}$ shows the mass spectrum of the same solution when $E_{B A T}=+3 \mathrm{~V}$ was applied resulting in $I_{W}=$ $+3.4 \mu \mathrm{A}$. This mass spectrum exhibited several peaks that corresponded in $\mathrm{m} / \mathrm{z}$ to reserpine oxidation products that could be observed in negative ion mode (Scheme 1c). The major peak in the spectrum was at $\mathrm{m} / \mathrm{z}$ 621 and corresponding to the $4 \mathrm{e}^{-}$oxidation product. The peak for reserpine anion $(\mathrm{m} / \mathrm{z} 607)$ was just visible in the spectrum. Using eq 2, the complete 4-electron oxidation of $5 \mu \mathrm{M}$ reserpine at $100 \mu \mathrm{L} / \mathrm{min}$ was calculated to require $+3.22 \mu \mathrm{A}$, which corresponds well with the measured value of $I_{W}(+3.4 \mu \mathrm{A})$ in this experiment.

This simple circuit was further tested by switching back and forth the polarity of $E_{B A T}$ while using single ion monitoring to observe the abundance of deprotonated reserpine and the $4 \mathrm{e}^{-}, 6 \mathrm{e}^{-}$, and $8 \mathrm{e}^{-}$oxidation products of reserpine (Figure $6 \mathrm{c}-\mathrm{f}$ ). These ion current profiles show reproducible multiple-electron reserpine oxidation using $E_{B A T}=+3 \mathrm{~V}$, and complete avoidance of oxidation when the battery polarity was reversed. Also, the response time of the system to adjust to the changing applied $E_{B A T}$ voltage was observed to be relatively fast $(<2 \mathrm{~s})$.

While the location of the battery in the circuit should not affect the observed analyte electrochemistry, in practical applications the current drain on the battery should be minimized. Figure 7a describes the detailed circuit used while recording the mass spectrum in Figure $6 \mathrm{~b}$. The current through the battery was $10.9 \mu \mathrm{A}$. By placing the battery in the working electrode leg (i.e., the high voltage connected to the auxiliary electrodes as shown in Figure $7 \mathrm{~b}$ ), the current drain on the battery would have been decreased to $3.4 \mu \mathrm{A}$. Figure $7 \mathrm{c}$ shows an easy upgrade to the currently used circuit, where a switch enables placing the battery either in the working or in the auxiliary electrode leg.

\section{Conclusions}

The implementation of a battery-powered, controlledcurrent two-electrode emitter system provides a simple, economical means for control over analyte electrochemical processes that take place in the emitter of an ES ion source. This modification of a regular electrospray emitter introduces an extra current loop into the system in addition to the upstream current loop (floated emitter to upstream ground point loop) and the electrospray

(a)

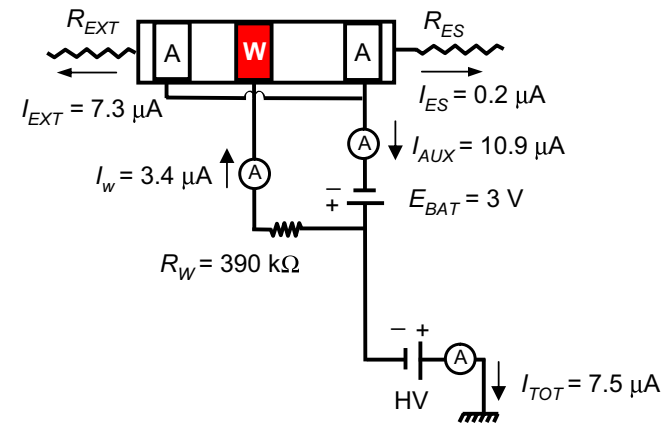

(b)

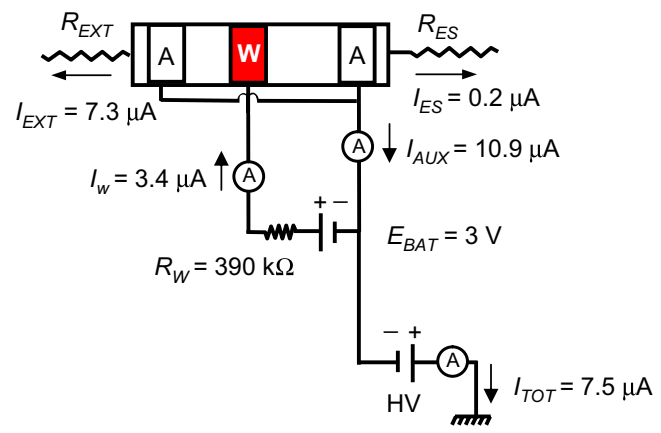

(c)

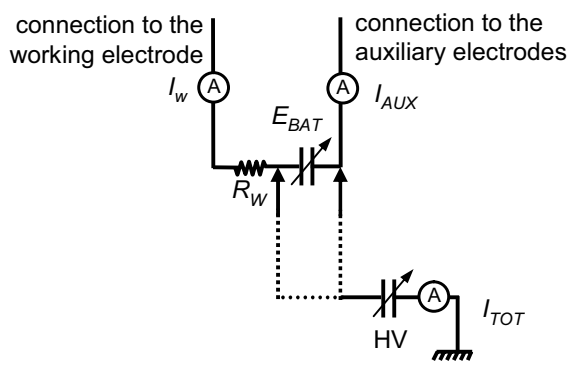

Figure 7. (a) Detailed diagram of the electrical circuit used for recording the mass spectrum in Figure $6 \mathrm{~b}$ showing the $I_{A U X}=10.9$ $\mu \mathrm{A}$ current drain on the battery. (b) Detailed diagram of an alternative electrical circuit that could be used to record the same mass spectrum as in Figure $6 \mathrm{~b}$ with decreased current drain on the battery $\left(I_{W}=3.4 \mu \mathrm{A}\right)$. (c) Diagram of another alternative electrical circuit with an additional double throw switch (positions indicated by the dotted arrows) to switch the battery between either the working or the auxiliary electrode leg. 
current loop (floated emitter to mass spectrometer counter electrode loop). The total emitter current $\left(I_{T O T}\right)$ divided between the working and auxiliary electrodes of the emitter cell can be manipulated by controlling the resistance between the ES high voltage lead and the corresponding electrodes. The measured working $\left(I_{W}\right)$ and auxiliary $\left(I_{A U X}\right)$ electrode currents are the sum of these individual partial inherent currents superimposed on $I_{B A T}$, the current produced by the battery. Effective analyte electrochemistry takes place only at the high surface area porous flow-through working electrode regardless of the current magnitude and polarity at the auxiliary electrode, because of the small total surface area of the four linked auxiliary electrodes. Thus, analyte oxidation or reduction with this cell was accomplished by controlling the polarity and magnitude of the current at the working electrode.

The analytical utility of the CCE-ES emitter was illustrated by demonstrating enhanced analyte oxidation in positive ion mode (enhance reduction in negative ion mode should also be possible), the ability to turn off analyte oxidation in positive ion mode (or reduction in negative ion mode), and the ability to reduce analytes in positive ion mode and oxidize analytes in negative ion mode. Thus, a simple and inexpensive battery and resistor circuit used with a two-electrode emitter cell provided the same basic electrochemical capabilities as a three-electrode emitter cell controlled by a sophisticated floated potentiostat $[10,11]$. Moreover, since the current requirements of a typical floated emitter ES system with an upstream ground contact are $10 \mu \mathrm{A}$ or less, a small-size watch battery with, e.g., $200 \mathrm{mAh}$ capacity could power the controlled-current cell in continuous use for over a year. By building and using a simple controlled-current circuit that included just a single resistor, polarity toggle switch, and a small-size $3 \mathrm{~V}$ watch battery, we were also able to demonstrate that the possibility exists to include all the CCE-ES emitter electronics on the body of the emitter cell.

\section{Acknowledgments}

ES-MS instrumentation and electrochemical cell and associated components, respectively, were provided through a Cooperative Research and Development Agreement with MDS SCIEX and ESA Biosciences, Inc. (CRADA no. ORNL02-0662). VK acknowledges an ORNL appointment through the ORNL Postdoctoral Research Associates Program. The work carried out at
ORNL was supported by the Division of Chemical Sciences, Geosciences, and Biosciences, Office of Basic Energy Sciences, United States Department of Energy under contract no. DEAC05-00OR22725 with ORNL, managed and operated by UTBattelle, LLC.

This manuscript has been authored by a contractor of the U.S. Government under contract no. DE-AC05-00OR22725. Accordingly, the U.S. Government retains a paid-up, nonexclusive, irrevocable, worldwide license to publish or reproduce the published form of this contribution, prepare derivative works, distribute copies to the public, and perform publicly and display publicly, or allow others to do so, for U.S. Government purposes.

\section{References}

1. Van Berkel, G. J. The Electrolytic Nature of Electrospray, Chap. II. In Electrospray Ionization Mass Spectrometry; Cole, R. B., Ed.; Wiley: New York, 1997; pp 65-105.

2. De la Mora, J. F.; Van Berkel, G. J.; Enke, C. G.; Cole, R. B.; MartinezSanchez, M.; Fenn, J. B. Electrochemical Processes in Electrospray Ionization Mass Spectrometry. J. Mass Spectrom. 2000, 35, 939-952.

3. Van Berkel, G. J. Insights into Analyte Electrolysis in an Electrospray Emitter from Chronopotentiometry Experiments and Mass Transport Calculations. J. Am. Soc. Mass Spectrom. 2000, 11, 951-960.

4. Diehl, G.; Karst, U. On-Line Electrochemistry-MS and Related Techniques. Anal. Bioanal. Chem. 2002, 373, 390-398.

5. Wang, J. Analytical Electrochemistry, 2nd ed.; Wiley-VCH: New York, NY, 2000.

6. Van Berkel, G. J.; Kertesz, V.; Ford, M. J.; Granger, M. C. Efficient Analyte Oxidation in an Electrospray Ion Source Using a Porous Flow-Through Electrode Emitter. J. Am. Soc. Mass Spectrom. 2004, 15, 1755-1766.

7. Van Berkel, G. J., Kertesz, V. Expanded Electrochemical Capabilities of the Electrospray Ion Source using Porous Flow-Through Electrodes as the Upstream Ground and Emitter High Voltage Contact. Anal. Chem., in press.

8. Van Berkel, G. J.; Zhou, F.; Aronson, J. T. Changes in Bulk Solution pH Caused by the Inherent Controlled-Current Electrolytic Process of an Electrospray Ion Source. Int. J. Mass Spectrom. Ion Processes 1997, 162, 55-67.

9. Van Berkel, G. J.; Kertesz, V. Redox Buffering in an Electrospray Ion Source Using a Copper Capillary Emitter. J. Mass Spectrom. 2001, 36, 1125-1132.

10. Van Berkel, G. J.; Asano, K. G.; Granger, M. C. Controlling Analyte Electrochemistry in an Electrospray Ion Source with a Three-Electrode Emitter Cell. Anal. Chem. 2004, 76, 1493-1499.

11. Kertesz, V.; Van Berkel, G. J.; Granger, M. C. Study and Application of a Controlled-Potential Electrochemistry-Electrospray Emitter for Electrospray Mass Spectrometry. Anal. Chem. 2005, 77, 4366-4373.

12. Xu, X.; Lu, W.; Cole, R. B. On-Line Probe for Fast Electrochemistry/ Electrospray Mass Spectrometry. Investigations of Polycyclic Aromatic Hydrocarbons. Anal. Chem. 1996, 68, 4244-4253.

13. Lu, W.; Xu. X.; Cole, R. B. On-Line Linear Sweep VoltammetryElectrospray Mass Spectrometry. Anal. Chem. 1997, 69, 2478-2484.

14. Zhou, F.; Van Berkel, G. J. Electrochemistry Combined On-Line with Electrospray Mass Spectrometry. Anal. Chem. 1995, 67, 3643-3649.

15. Zhang, T.; Palii, S. P.; Eyler, J. R.; Brajter-Toth, A. Enhancement of Ionization Efficiency by Electrochemical Reaction Products in On-Line Electrochemistry/Electrospray Ionization Fourier Transform Ion Cyclotron Resonance Mass Spectrometry. Anal. Chem. 2002, 74, 1097-1103.

16. http://www.duracell.com

17. Nicolai, S. H. D.; Rodrigues, P. R. P.; Agostinho, S. M. L.; Rubim, J. C. Electrochemical and Spectroelectrochemical (SERS) Studies of the Reduction of Methylene Blue on a Silver Electrode. J. Electroanal. Chem. 2002, 527(1/2), 103-111. 